\title{
Histopathological examination of specimens removed during directional coronary atherectomy in patients presenting with crescendo angina show mural thrombus
}

\author{
Christopher M. Bellamy, Ever D. Grech, Michael T. Ashworth and David R. \\ Ramsdale
}

Cardiology Research Department, The Cardiothoracic Centre, NHS Trust, Thomas Drive, Liverpool L14 3PE, UK

\begin{abstract}
Summary: Thrombus formation over a fissured coronary atheromatous plaque has been shown by post mortem histological examination to be the pathophysiological mechanism responsible for myocardial ischaemia in those patients who died following a crescendo pattern of angina. Histological examination of plaques responsible for a crescendo pattern of angina in patients who do not die has not been available until recently. We describe two patients who presented with a crescendo pattern of angina. A new technique of coronary revascularization, directional coronary atherectomy, produced symptomatic relief and resolution of myocardial ischaemia. Histological examination of material from the stenosis responsible for their myocardial ischaemia, obtained using this technique, confirmed thrombus formation overlying a fissured atheromatous plaque.
\end{abstract}

\section{Introduction}

In patients dying following a crescendo history of angina pectoris, post mortem histopathological studies have shown that such patients have a fissured atheromatous plaque with overlying thrombus formation in the ischaemia-related coronary artery. ${ }^{1}$ However, patients who die following a crescendo history of angina represent a small subset of patients presenting with such a history. Although coronary angiographic ${ }^{2}$ and angioscopic ${ }^{3}$ studies suggest thrombus formation overlying a fissured plaque may be the mechanism responsible for symptoms in patients not dying of crescendo angina, until recently histopathology material has not been available for examination. Directional coronary atherectomy is a new percutaneous technique for coronary revascularization. During this procedure the coronary stenosis responsible for the myocardial ischaemia is selectively debulked by a cutting device in the biopsy housing of the atherectomy catheter and this material is pushed into the catheter's nose cone. Debulking of the lesion results in increased coronary blood flow and resolution of the symptoms. One advantage of this procedure over other methods of revascularization is that the material responsible for the stenosis is retrieved and can undergo subsequent histopathological examination.

Correspondence: C.M. Bellamy, M.R.C.P. Accepted: 23 July 1992
We describe two patients with a history of̂. $a^{\omega}$ crescendo pattern of angina in whom coronatyo angiography showed complex stenoses in the prox imal left anterior descending coronary artery. Percutaneous directional atherectomy produced symptomatic relief and resolution of myocardia $\mathbb{R}$ ischaemia. Histopathological examination of the $\vec{F}$ material obtained at atherectomy showed speci- 3 mens consistent with thrombus formation over fissured atheromatous plaque.

\section{Case 1}

A 41 year old woman was admitted with a one week history of anginal chest pain occuring on minima $\mathrm{R}^{2}$ exertion and at rest. A resting electrocardiogram showed T wave inversion in leads V2, V3 and AVL $>$ Cardiac enzymes remained in the normal range? Coronary angiography showed an eccentric steno-N sis in the proximal left anterior descending artery with a minimal luminal diameter at the stenosis of $1.2 \mathrm{~mm}$ in a vessel measuring $3.7 \mathrm{~mm}$ (Figure 1a). $\omega$

Following pretreatment with aspirin $300 \mathrm{mg}$ and intravenous heparin 10,000 units, an 11 Frencho guiding catheter was advanced to the left coronaryo ostium. A 7 French atherectomy device (Devices ${ }^{+}$ for Vascular Intervention, Redwood City, California, USA) was placed across the lesion and fouro cuts across the lesion were made. This produced a? 
good angiographic result with a minimal luminal stenosis diameter at the lesion of $3.4 \mathrm{~mm}$ (vessel diameter also increased to $4.4 \mathrm{~mm}$ ) (Figure $1 \mathrm{~b}$ ).

Four specimens of tissue were retrieved from the cutting chamber. In one specimen the media showed some fibrosis and the attached intima in this fragment exhibited moderate fibro-elastic thickening. Towards the luminal surface the tissue was more fibrous. Small platelet thrombi without organization were attached to the surface (Figure 1c). The remaining three pieces consisted of loose tissue containing myofibroblasts, foam cells, capillary blood vessels and a few scattered lymphocytes and extravasated erythrocytes. The appearances were those of a fissured plaque with attached platelet thrombus.

\section{Case 2}

A 61 year old man presented with a 2 month history of progressive effort angina. A resting electrocardiogram showed sinus bradycardia of 49 beats per minute but no ischaemic changes. Exercise electrocardiography produced symptoms and ischaemic changes during the second minute of a Bruce treadmill protocol. Coronary angiography showed an eccentric, complex proximal left anterior descending artery stenosis with the minimal luminal diameter at the stenosis measuring $0.7 \mathrm{~mm}$ diameter in a $3.0 \mathrm{~mm}$ diameter vessel. There was a lesser eccentric stenosis just distal to this lesion and there were also vessel wall irregularities in the right coronary artery. Following 10,000 units of intravenous heparin the cutting blade of a 7 French coronary atherectomy device was advanced five times across the proximal lesion and twice at the distal lesion. The post-procedure angiogram showed a good angiographic result with the proximal stenosis minimal luminal diameter measuring $2.6 \mathrm{~mm}$ (vessel diameter increased to $3.1 \mathrm{~mm}$ ).

Five specimens were retrieved from the cutting chamber. Histology showed one to consist of a fissured fibrous plaque with adherent platelet thrombus with the suggestion of early organization (Figure 2). The remaining specimens consisted of laminated, poorly cellular collagenous fibrous tissue with some attached looser tissue containing myofibroblasts and a few foam cells. Thin irregular elastic fibres could be identified in the fibrous tissue.

\section{Discussion}

These two patients presented with a history of rapidly increasing frequency and severity of anginal symptoms. Using Braunwald's recently proposed clinical classification of unstable angina ${ }^{4}$
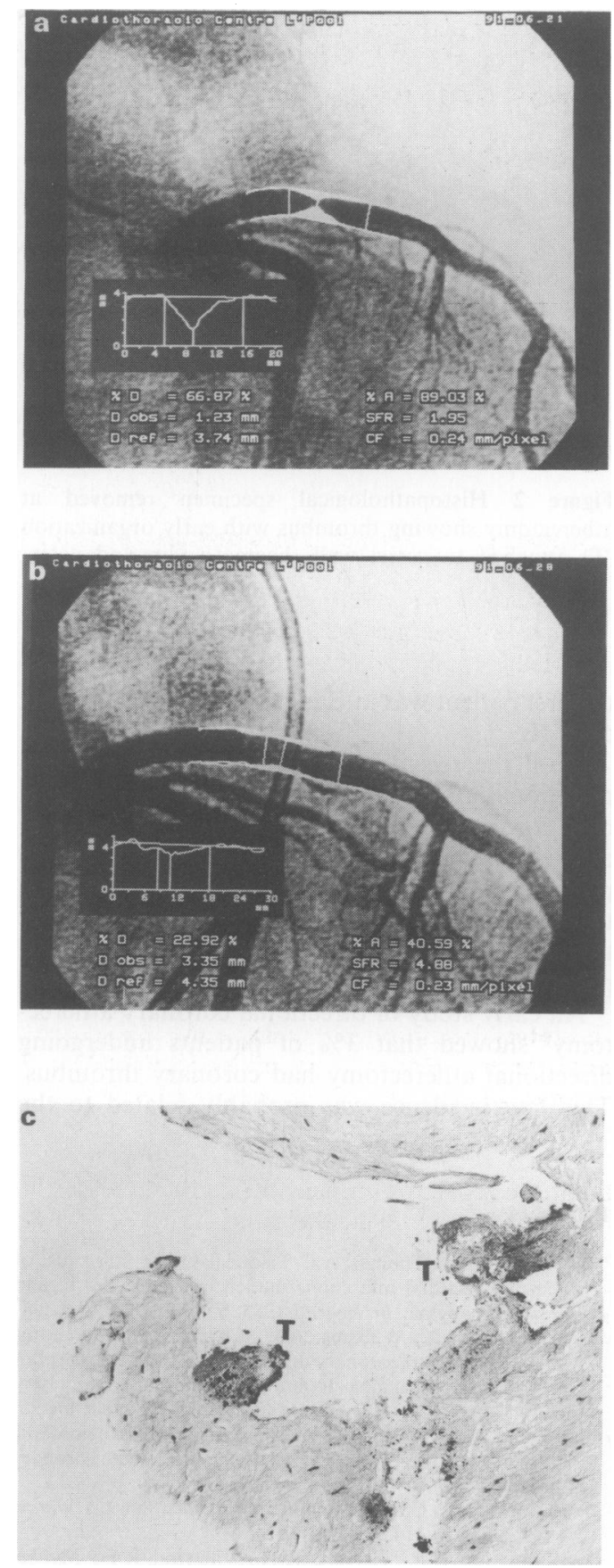

Figure 1 (a) Digitally enhanced coronary angiogram $\left(35^{\circ}\right.$ right anterior oblique projection) showing eccentric stenosis in left anterior descending coronary artery. (b) Angiographic appearance following coronary atherectomy (same projection). (c) Histopathological specimen removed at atherectomy showing platelet thrombi (T) attached to disrupted intima (haematoxylin and eosin, $\times 20)$. 


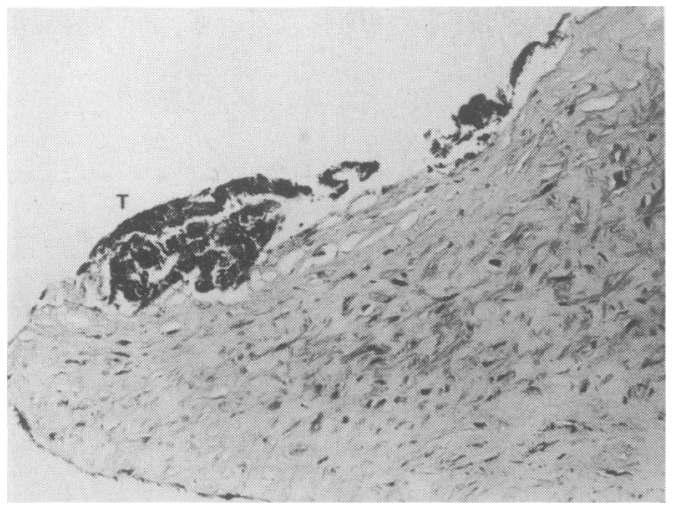

Figure 2 Histopathological specimen removed at atherectomy showing thrombus with early organization (T) attached to vessel wall (haematoxylin and eosin, $\times 50)$.

the first patient was in class IIIB and the second in class IB.

Until the recent introduction of percutaneous directional atherectomy, histological examination of a coronary artery stenosis responsible for the coronary ischaemia has not been available in living patients. Initial experience with percutaneous transluminal directional atherectomy has shown it to be a safe and effective method for managing proximal coronary stenoses. ${ }^{5-7}$

An early study of directional coronary atherectomy ${ }^{8}$ showed that $3 \%$ of patients undergoing directional atherectomy had coronary thrombus. This low incidence was probably related to the

\section{References}

1. Davies, M.J. \& Thomas, A.C. Plaque fissuring - the cause of acute myocardial infarction, sudden ischaemic death, and crescendo angina. Br Heart J 1985, 53: 363-373.

2. Freeman, M.R., Williams, A.E., Chisholm, R.J. \& Armstrong, P.W. Intracoronary thrombus and complex morphology in unstable angina. Relation to timing of angiography and in-hospital cardiac events. Circulation 1989, 80: 17-23.

3. Mizuno, K., Miyamoto, A., Satomura, K. et al. Angioscopic coronary macromorphology in patients with acute coronary disorders. Lancet 1991, 337: 809-812.

4. Braunwald, E. Unstable angina. A classification. Circulation 1989, 80: 410-414.

5. Kaufmann, U.P., Garratt, K.N., Vlietstra, R.E., Menke, K.K. \& Holmes, D.R., Jr. Coronary atherectomy: first 50 patients at the Mayo Clinic. Mayo Clin Proc 1989, 64: 747-752.

6. Safian, R.D., Gelbfish, J.S., Erny, R.E., Schnitt, S.J., Schmidt, D.A. \& Baim, D.S. Coronary atherectomy. Clinical, angiographic, and histological findings and observations regarding potential mechanisms. Circulation 1990, 82: 6979. selection of patients with stable symptoms. $A \stackrel{a}{2}$ recent series showed thrombus formation in $48 \%$ of patients, ${ }^{9}$ however, the authors did not correlate the finding of coronary thrombus with the clinicaldiagnosis.

This case report confirms by histology the presence of platelet-rich intracoronary thrombus ine patients presenting with a crescendo history of angina. Angioscopy has shown that the appearance of thrombus formation occurring in unstable cor 0 onary syndromes has a whitish appearance, where as in patients with myocardial infarction the thrombus is red. ${ }^{10}$ The whitish appearance suggests a platelet-rich thrombus whereas a red thrombus isw fibrin and erythrocyte rich. The finding of platelet $\frac{5}{8}$ rich thrombus in unstable coronary syndromes? may have implications for therapy as such thrombir. may not be as susceptible to thrombolytic therapye as fibrin rich thrombi. This may explain whyo thrombolytic therapy has been less effective in ${ }^{\circ}$ unstable angina than in myocardial infarction.

Percutaneous coronary angioplasty is associate $d \vec{b}$ with a higher peri-procedural complication rate in? patients who have coronary artery thrombus com $\vec{T}$ pared to those who do not. Recent evidence向 suggests that directional coronary atherectomy has? a lower procedural complication rate than angio plasty in patients with thrombus-containi lesions. ${ }^{11}$ This may be due to the fact that duringe directional coronary atherectomy the lesionois removed whereas during percutaneous translurmi nal angioplasty the lesion is just remodelled and this may leave a focus for further thrombus forma tion.

Directional coronary atherectomy is an effective尺 treatment for some patients with unstable angina $\overrightarrow{\overrightarrow{0}}$

7. Hinohara, T., Rowe, M.H., Robertson, G.C. et al. Effect of lesion characteristics on outcome of directional coronary atherectomy. J Am Coll Cardiol 1991, 17: 1112-1120.

8. Garratt, K.N., Edwards, W.D., Kaufmann, U.P., Vlietstra R.E. \& Holmes, D.R., Jr. Differential histopathology of primary atherosclerotic and restenotic lesions in coronary arteries and saphenous vein bypass grafts: analysis of tissue obtained from 73 patients by directional atherectomy. $J \mathrm{Am}_{\square}$ Coll Cardiol 1991, 17: 442-448.

9. Schnitt, S.J., Safian, R.D., Kuntz, R.E., Schmidt, D.A. \& Baim, D.S. Histologic findings in specimens obtained by $N$ percutaneous directional coronary atherectomy. Hum Path 1992, 23: 415-420.

10. Mizuno, K., Satomura, K., Miyamoto, A. et al. Angioscopio evaluation of coronary-artery thrombi in acute coronary $\omega$ syndromes. N Engl J Med 1992, 326: 287-291.

11. Holmes, D.R., Ellis, S.G. \& Garratt, K.N. Directionado coronary atherectomy for thrombus containing lesions $\frac{\Gamma}{\mathrm{D}}$ Improved outcome. Circulation 1991, 84 (Suppl II): 260 (Abstract). 